\title{
Peningkatan Kestabilan Pilar Tambang Bawah Tanah Marmer di PT Gunung Marmer Raya
}

\author{
Purwanto*, Nirmana Fiqra Qaidahiyani, Djamaluddin, Aryanti Virtanti Anas, Muhammad Ramli, \\ Muhammad Antariruanda \\ Universitas Hasanuddin \\ purwanto@unhas.ac.id*
}

\begin{abstract}
Abstrak
PT Gunung Marmer Raya (PT GMR), merupakan tambang marmer bawah tanah dengan metode room and pillar yang terletak di sekitar $73 \mathrm{~km}$ sebelah utara Kota Makassar, di Desa Tabo-Tabo, Kecamatan Bungoro, Kabupaten Pangkep. Bidang diskontinyu berupa rekahan dijumpai memotong area produksi. Kegiatan pengabdian ini bertujuan untuk membuat desain ulang pilar sebagai upaya meningkatkan kestabilan tambang bawah tanah. Kegiatan ini dimulai dengan observasi lapangan, menentukan karakteristik batuan, melakukan klasifikasi massa batuan dengan Q-system hingga merancang kembali disain pilar untuk meningkatkan kestabilan tambang marmer bawah tanah tersebut. Berdasarkan perhitungan klasifikasi massa batuan menggunakan Q-System, rekomendasi penyanggaan adalah systematic bolting dan fibre reinforced sprayed concrete setebal $5-6 \mathrm{~cm}$ dengan jarak spasi antar-bolt 2,2 meter, atau systematic bolting tanpa lapisan concrete dengan jarak spasi antar-bolt 1,8 meter. Pemantauan kekar, utamanya pada pilar, perlu dilakukan secara rutin agar pergerakan kekar dapat diantisipasi jika menunjukkan pergerakan yang progresif. Dimensi panjang dan lebar pilar sebelumnya adalah $5 \mathrm{~m}$ x $5 \mathrm{~m}$ tidak direkomendasikan karena estimasi faktor keamanan yang dihasilkannya bernilai di bawah 1 (tidak aman). Berdasarkan hasil observasi dan perhitungan analitik, untuk ketinggian pilar hingga 11 meter diperoleh rekomendasi panjang dan lebar pilar yaitu $5 \mathrm{~m}$ x $9 \mathrm{~m}$ untuk chain pillar estimasi faktor keamanan 1,35-1,49; dan barrier pillar $5 \mathrm{~m}$ x $12 \mathrm{~m}$ estimasi faktor keamanan 1,58-1,74.
\end{abstract}

Kata Kunci: Tambang bawah tanah; metode room and pillar; sistem klasifikasi Q-system; kestabilan pilar; tambang marmer

\begin{abstract}
PT Gunung Marmer Raya (PT GMR), a room and pillar underground marble mining is located about $73 \mathrm{~km}$ to the north from Makassar, in Desa Tabo-Tabo, Kecamatan Bungoro, Kabupaten Pangkep. In the mining location, discontinuities are found as joint structure across the production area. The purpose of this service is to make pillar redesign that can improve the stability of underground mine. These activities start with field observation, determining the rock characteristic through sample testing in the laboratory, classifying the rock mass using $Q$ system method, up to redesigning a form of implementation to increase the stability of the marble underground mine. According to calculation of rock mass classification using Q-System, the recommended buffering is systematic bolting and fiber reinforced sprayed concrete as thick as 5-6 cm with spacing between bolts of 2.2 meters, or systematic bolting without concrete layering with spacing between-bolt 1.8 meter. Joint monitoring, especially on pillars, need to be done routinely so joint movement could be anticipated for progressive movement. The existing dimensions of pillar $5 \mathrm{~m} \times 5 \mathrm{~m}$ in length and width is not recommended due to the safety factor is under 1,0 (unstable condition). Based on observation and analytic calculation, for each pillar height of up to 11 meters the pillar is recommended to redesign with length and width $5 \mathrm{~m} \times 9 \mathrm{~m}$ for the chain pillar (safety factor around 1.351.49); and $5 \mathrm{~m} \times 12 \mathrm{~m}$ for barrier pillars (safety factor around 1.58-1.74).
\end{abstract}

Key Words: Underground mining; room and pillar method; Q-system classification system; pillar stability; marble mining.

\section{Pendahuluan}


Sistem penambangan bawah tanah (underground mining) merupakan sistem penambangan yang ditujukan pada bahan galian yang tidak ekonomis di tambang jika dilakukan dengan sistem tambang terbuka, baik bahan galian batu bara maupun bahan galian bijih, atau pada bahan galian yang terletak di bawah hutan lindung, seperti yang telah tertuang pada Peraturan Pemerintah Nomor 24 Tahun 2010 tentang Penggunaan Kawasan Hutan dan Peraturan Presiden Nomor 28 tahun 2011 tentang Penggunaan Kawasan Hutan Lindung untuk Penambangan Bawah Tanah. Aplikasi tambang bawah tanah pada endapan marmer masih jarang digunakan. Sistem tambang bawah tanah ini memiliki beberapa kelebihan dibandingkan dengan sistem tambang permukaan, antara lain sebagai berikut:

a. Marmer yang diperoleh dalam keadaan lebih segar, pelapukan di bawah permukaan terjadi lebih sedikit dibandingkan marmer yang terletak di permukaan; dan

b. Dampak lingkungan yang dihasilkan lebih sedikit dibandingkan dengan sistem tambang terbuka yang dapat mengubah bentang alam di permukaan secara langsung.

Tujuan kegiatan pengabdian ini adalah untuk meningkatkan kestabilan pilar tambang marmer bawah tanah di PT Gunung Marmer Raya (PT GMR) sehingga aktivitas produksi dapat berlanjut, standar Kesehatan dan Keselamatan Kerja (K3) pun terpenuhi sehingga terwujud lingkungan kerja yang aman dan nyaman.

Tampak citra satelit area pertambangan PT Gunung Marmer Raya (PT GMR) dapat dilihat pada Gambar 1.

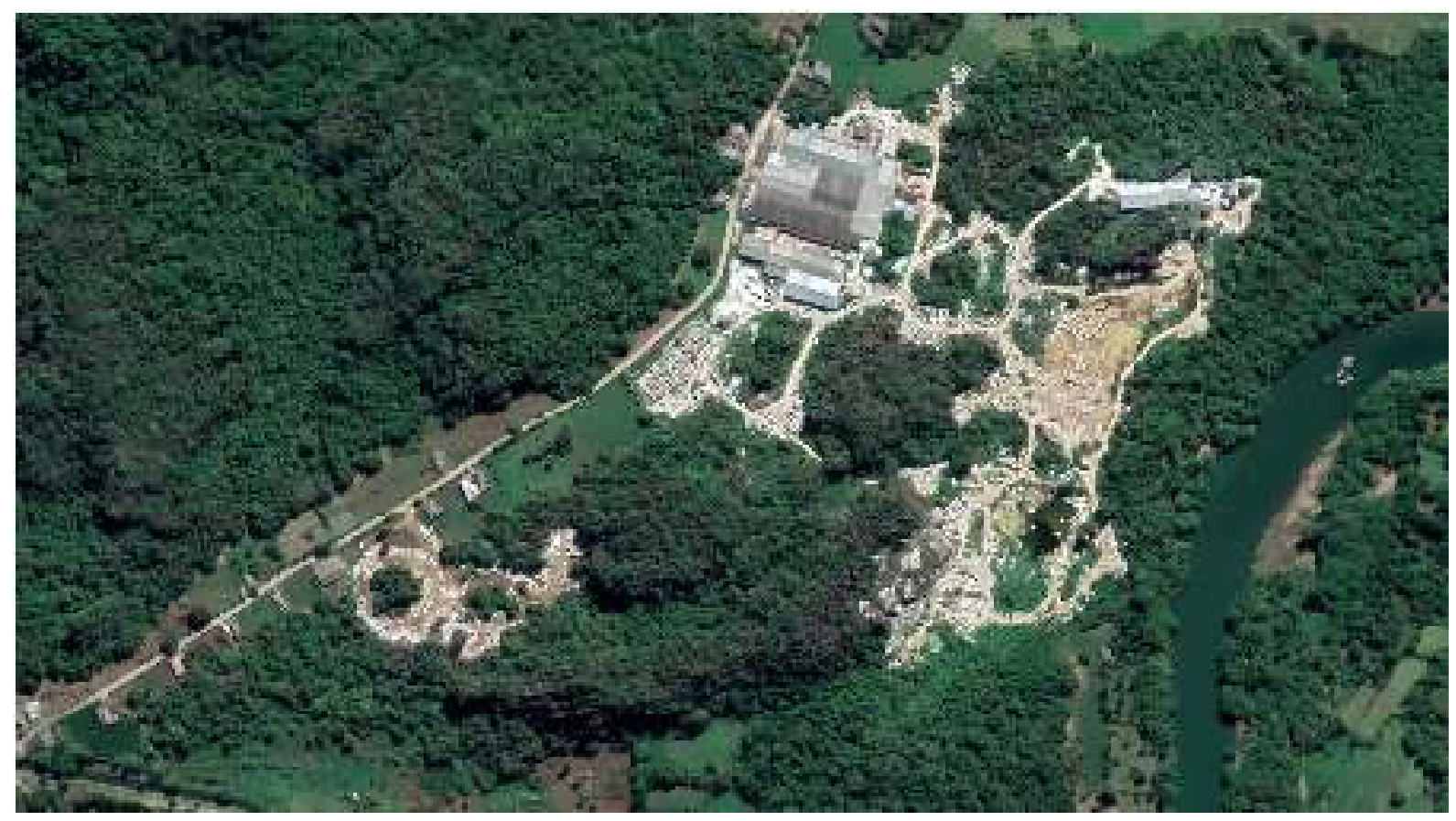

Gambar 1. Tampak Citra Satelit Area Pertambangan PT Gunung Marmer Raya (PT GMR), 2019. Diambil pada Tanggal 22 Juni 2019

\section{Sistem Penambangan dan Pertimbangan Geoteknik pada Tambang Bawah Tanah}

Sistem penambangan bawah tanah umumnya dilakukan apabila sistem penambangan permukaan tidak memungkinkan. Hal tersebut karena sistem penambangan bawah tanah umumnya membutuhkan biaya operasi yang lebih tinggi, penggunaan alat-alat yang terbatas, 
ketidakstabilan tambang yang lebih tinggi, dan kebutuhan penyanggaan untuk meningkatkan kestabilan yang lebih kompleks dibandingkan dengan sistem penambangan permukaan.

Jenis tambang marmer bawah tanah PT GMR ini adalah tambang bawah tanah swasangga dengan metode room and pillar. Pada kondisi awal ketika batuan belum mengalami ekskavasi, tegangan yang bekerja pada tempat tersebut berada pada kondisi stabil. Namun, ketika ekskavasi lubang bawah tanah dilakukan, tegangan yang bekerja di sekitar lubang bukaan akan mengalami gangguan dan terkonsentrasi di sekitar lubang bukaan tersebut. Gambar 2 memperlihatkan distribusi tegangan di sekitar lubang bukaan.

Metode tambang bawah tanah room and pillar umumnya digunakan pada tambang dengan potensi cebakan yang relatif datar seperti pada tambang batu bara dan marmer. Pada metode ini, desain penambangan berbentuk blok-blok persegi dengan menyisakan sebagian bahan galian sebagai pilar-pilar yang berfungsi untuk mendukung kestabilan tambang bawah tanah tersebut.

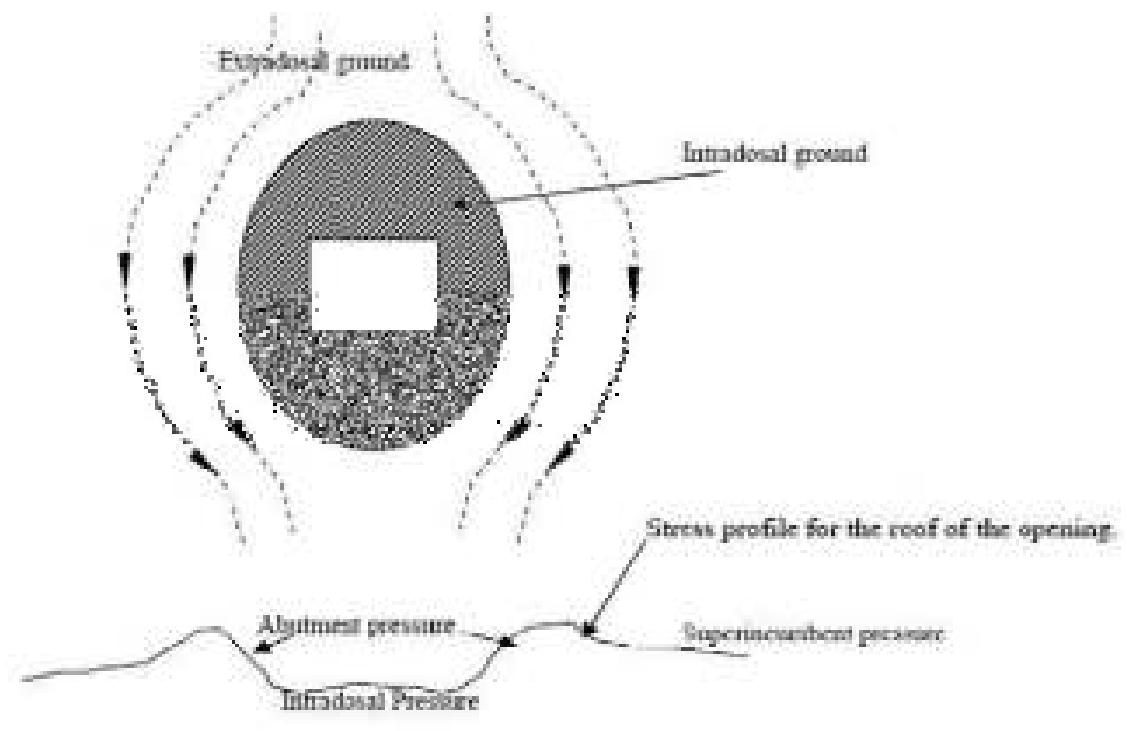

Gambar 2. Teori Busur Tekanan (Bieniawski, 1984)

Pada tambang bawah tanah dengan metode room and pillar, kestabilan tambang dipengaruhi oleh beberapa faktor, yaitu tegangan yang bekerja, beban vertikal lapisan penutup, kondisi massa batuan, kedalaman penambangan, dan kekuatan pilar. Sebagai penyangga yang menopang tambang bawah tanah, ukuran pilar ditentukan berdasarkan beban atap/overburden material di atasnya. Selain itu, kondisi massa batuan dan kekuatan pilar penyangga juga sangat penting diperhatikan.

Perhitungan kestabilan pilar menggunakan redistribusi tegangan berdasarkan prinsip tributary area (Bieniawski, 1984., Kum 2014) meliputi:

a. yang diasumsikan sebagai tekanan vertikal $(\mathrm{Po})$ yang tergantung berat dari massa batuan penutup;

$P_{o}=\gamma h$

dengan

$P_{o}=$ tekanan vertikal

$\gamma=$ berat volume massa batuan 
$h$ = kedalaman dari permukaan; dan

b. setiap pilar yang menyangga massa batuan di atasnya sesuai dengan luas pilar tersebut ditambah sebagian lainnya yang dibagi bebannya oleh pilar yang lain.

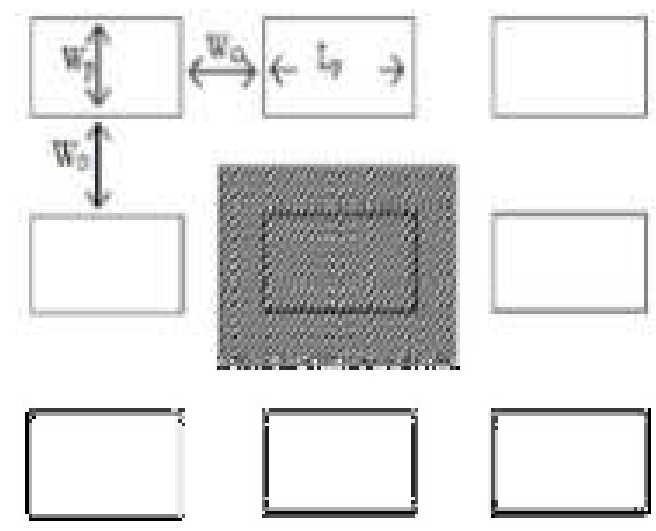

Gambar 3. Konsep Tributary Area pada Pembebanan Pilar (Bieniawski, 1984)

Beban pada pilar (P) dihitung melalui persamaan

$$
P=\left(L_{p}+W_{o}\right) x\left(W_{p}+W_{o}\right) x \gamma \cdot h
$$

dan tegangan pada pilar $\left(\mathrm{s}_{\mathrm{p}}\right)$ adalah sebagai berikut.

$$
\begin{aligned}
\sigma_{p} & =P /(\text { Luas Pilar })=\left(\left(L_{p}+W_{o}\right) \times\left(W_{p}+W_{o}\right) \times \gamma \cdot h\right) /\left(\left(L_{p} * W_{p}\right)\right) \\
\sigma_{p} & =\left(\left(L_{p}+W_{o}\right) x\left(W_{p}+W_{o}\right) x \sigma_{v}\right) /\left(\left(L_{p}{ }^{*} W_{p}\right)\right)
\end{aligned}
$$

\section{Metode untuk Menangani Permasalahan}

Pada perencanaan penyanggaan tambang bawah tanah, perlu dilakukan beberapa kegiatan sebagai berikut.

i. Kegiatan Lapangan

Melakukan kajian geoteknik pada area penambangan dengan metode tambang bawah tanah meliputi pemetaan kondisi massa batuan dan pengambilan contoh batuan (coring) untuk uji laboratorium. Berdasarkan hasil kegiatan lapangan, analisis klasifikasi massa batuan dilakukan sebagai salah satu faktor yang memengaruhi kestabilan tambang bawah tanah dan rencana desain penyanggaan. Pada kegiatan ini klasifikasi massa batuan yang digunakan adalah Q-system Tunneling Quality Index (Barton, 2015). 
(a)

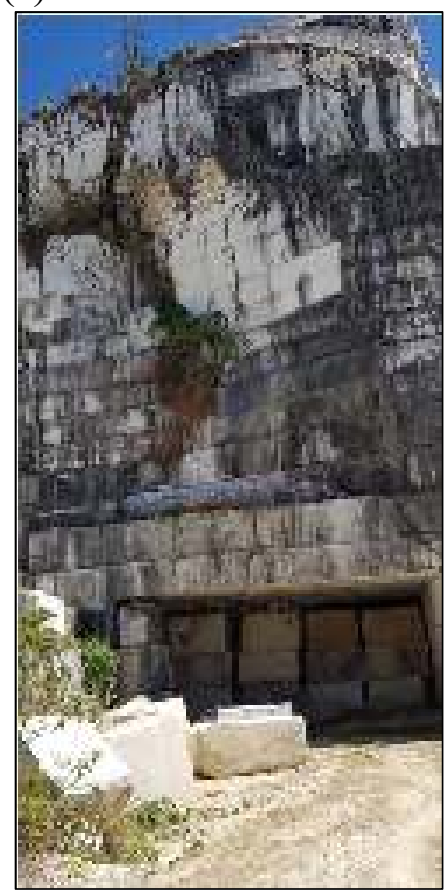

(c)

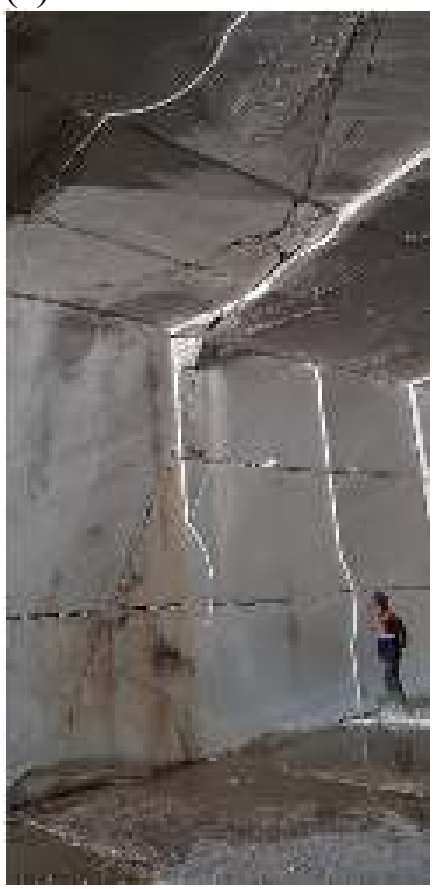

(b)

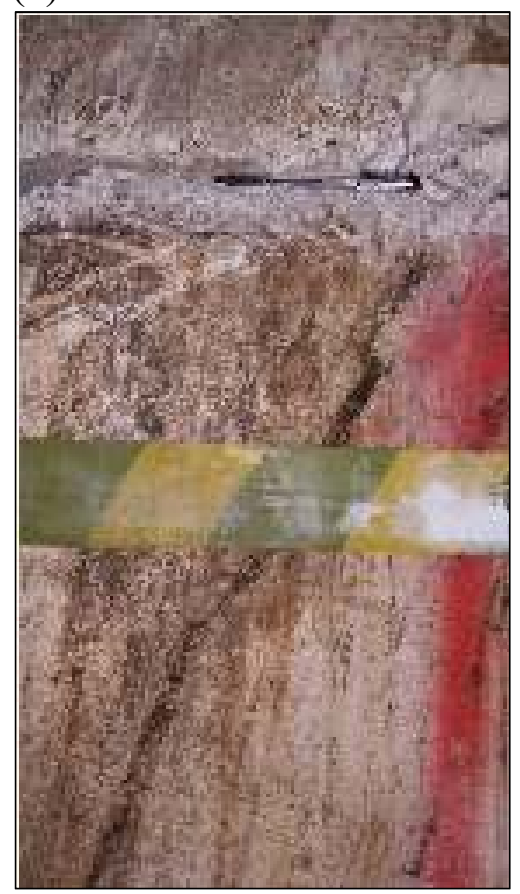

(d)

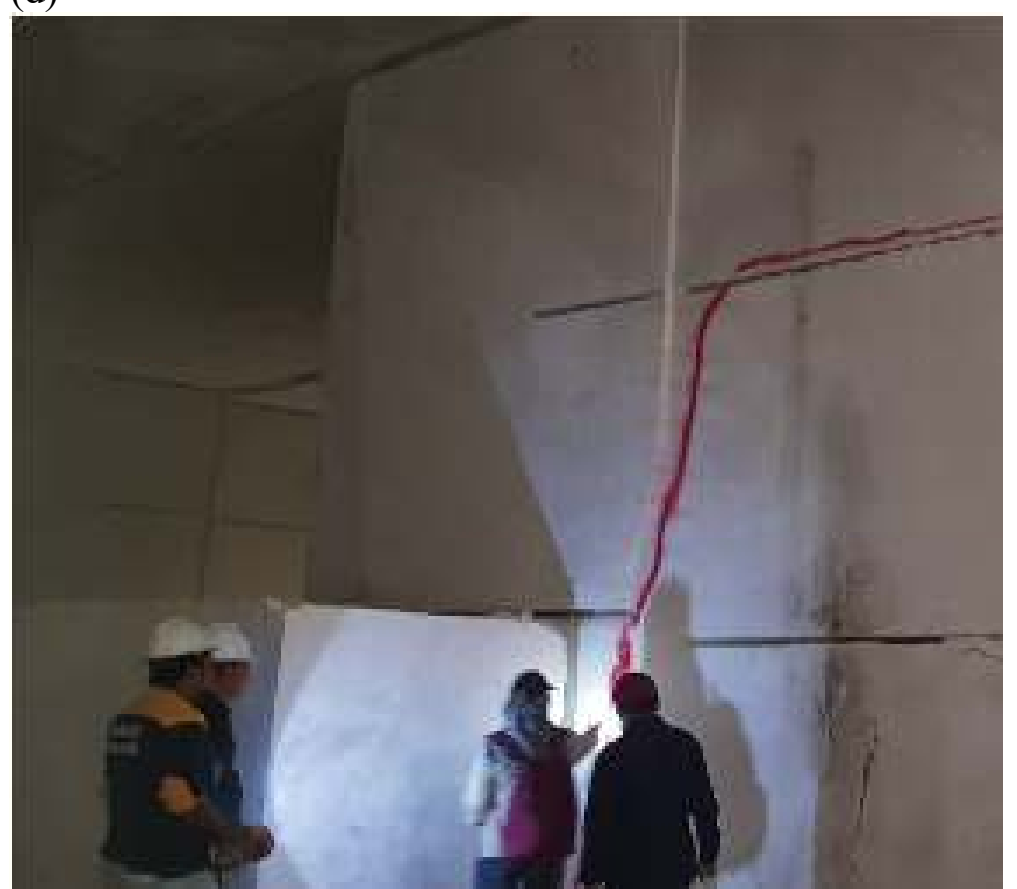

Gambar 4. Kondisi Tambang Marmer Bawah Tanah PT Gunung Marmer Raya (PT GMR);

(a) Kondisi Portal Tambang Marmer Bawah Tanah dan Kekar yang Terlihat dari Luar; (b sampai d) Kondisi Kekar Utama pada Lubang Bukaan 
ii. Kegiatan Laboratorium

Tujuan dari kegiatan laboratorium adalah untuk mendapatkan sifat fisik dan mekanis batuan. Data-data yang diperoleh dari kegiatan ini sangat dibutuhkan untuk analisis kestabilan dan desain penyanggaan tambang bawah tanah. Kegiatan uji laboratorium meliputi uji sifat fisik batuan dan uji sifat mekanis batuan. Dari hasil uji laboratorium akan diperoleh sifat fisik batuan yang meliputi densitas batuan, angka pori, dan porositas batuan. Adapun data yang diperoleh dari uji sifat mekanis batuan di laboratorium berupa nilai kuat tekan batuan $\left(\sigma_{c}\right)$ dan modulus elastisitas batuan $(E)$.

iii. Analisis Desain Penyanggaan

Desain penyanggaan akan dianalisis menggunakan metode empiris untuk kebutuhan material penyanggaan yang dibutuhkan.
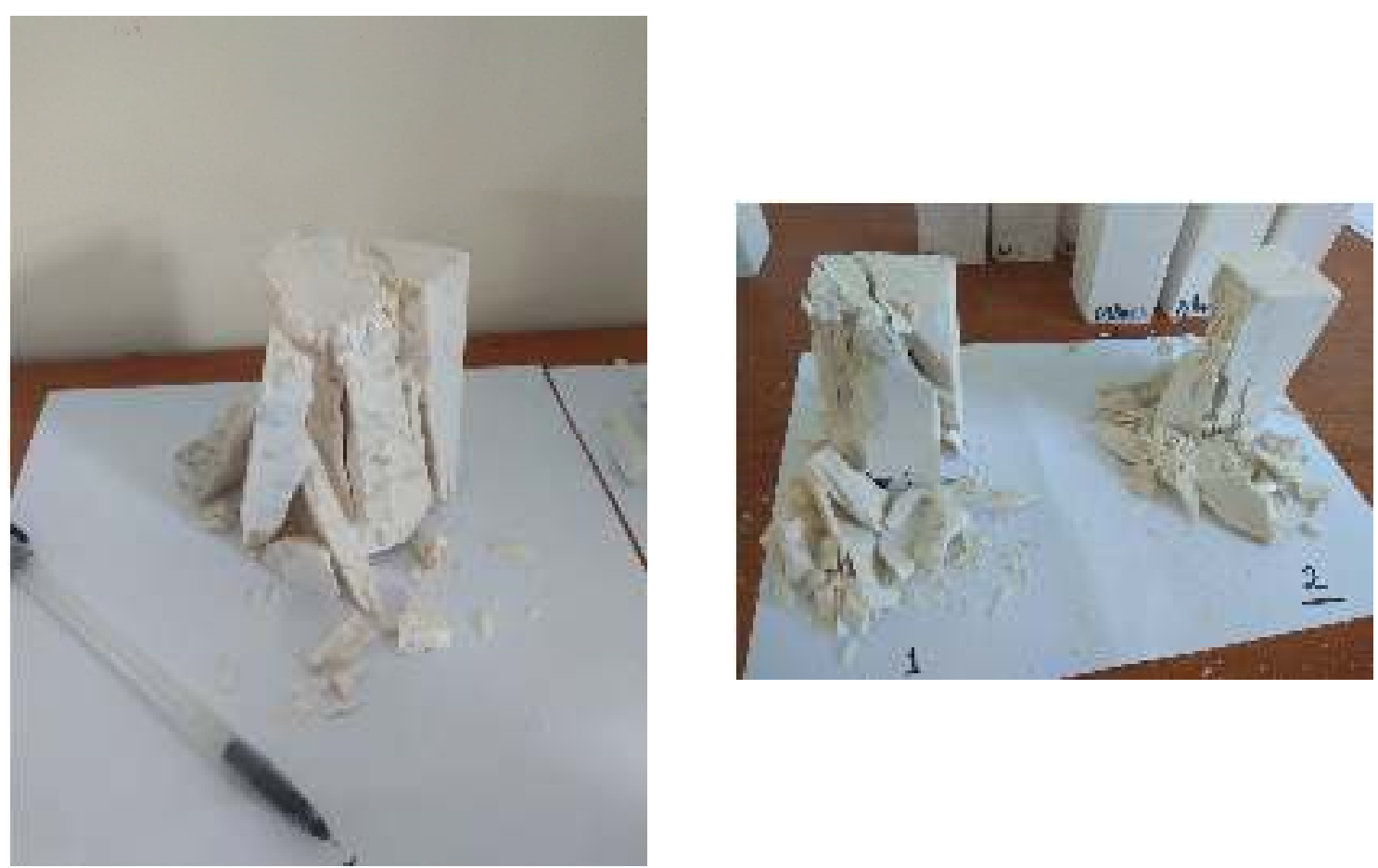

Gambar 5. Sampel Batuan Marmer yang Telah Diuji di Laboratorium Geomekanika UNHAS untuk Mendapatkan Nilai Kuat Tekan Uniaksial atau Kekuatan Batuan pada Tambang Marmer PT Gunung Marmer Raya (PT GMR)

\section{Hasil dan Diskusi}

Hasil uji sifat fisik sampel batuan dari tambang marmer PT Gunung Marmer Raya (PT GMR) ditunjukkan pada Tabel 1. 
Tabel 1. Rekapitulasi Hasil Uji Sifat Fisik pada Sampel Batuan Tambang Marmer PT Gunung Marmer Raya (PT GMR)

\begin{tabular}{crrrcccc}
\hline No. & $\begin{array}{c}\boldsymbol{\rho}_{\boldsymbol{n}} \\
\left(\mathbf{g r} / \mathbf{c m}^{\mathbf{3}}\right)\end{array}$ & $\begin{array}{c}\boldsymbol{\rho}_{\boldsymbol{d}} \\
\left(\mathbf{g r} / \mathbf{c m}^{\mathbf{3}}\right)\end{array}$ & $\begin{array}{c}\boldsymbol{\rho}_{\boldsymbol{s}} \\
\left(\mathbf{g r} / \mathbf{c m}^{\mathbf{3}}\right)\end{array}$ & $\begin{array}{c}\boldsymbol{W} \\
\mathbf{\%}\end{array}$ & $\begin{array}{c}\boldsymbol{S} \\
\mathbf{\%}\end{array}$ & $\begin{array}{c}\boldsymbol{n} \\
\mathbf{\%}\end{array}$ & $\boldsymbol{e}$ \\
\hline 1 & 2,22 & 2,22 & 2,23 & 0,000 & 0,00 & 0,01 & 0,0001 \\
2 & 2,19 & 2,19 & 2,20 & 0,000 & 0,00 & 0,01 & 0,0001 \\
3 & 2,42 & 2,42 & 2,44 & 0,003 & 0,33 & 0,02 & 0,0002 \\
4 & 2,70 & 2,70 & 2,71 & 0,001 & 0,25 & 0,01 & 0,0001 \\
\hline Rerata & 2,38 & 2,38 & 2,39 & 0,001 & 0,15 & 0,01 & 0,0001 \\
\hline
\end{tabular}

Keterangan:

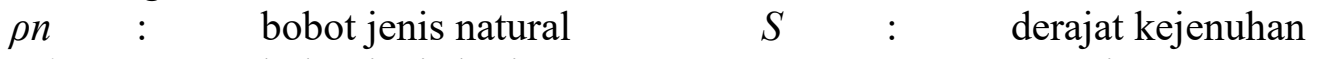

$\rho d \quad$ : bobot jenis kering $n:$ porositas

$\rho s \quad: \quad$ bobot jenis jenuh $\quad e \quad: \quad$ void ratio

$W \quad$ : $\quad$ kadar air natural

Hasil uji kuat tekan uniaksial batuan tambang marmer PT Gunung Marmer Raya (PT GMR) ditunjukkan pada Tabel 2.

Tabel 2. Rekapitulasi Hasil Uji Kuat Tekan Uniaksial pada Sampel Batuan Tambang Marmer PT Gunung Marmer Raya (PT GMR)

\begin{tabular}{ccrr}
\hline No. & Kode Sampel & UCS (MPa) & E (MPa) \\
\hline 1 & P1 & 19,72 & 2069,98 \\
2 & P2 & 17,71 & 2329,15 \\
3 & P3 & 19,23 & 4309,65 \\
4 & P4 & 17,26 & 2531,23 \\
5 & P5 & 22,43 & 5218,94 \\
6 & M1 & 18,55 & 3617,81 \\
7 & M2 & 17,71 & 1412,06 \\
8 & M3 & 23,83 & 4485,59 \\
9 & M4 & 20,24 & 5987,52 \\
10 & M5 & 13,97 & 3792,74 \\
\hline \multicolumn{2}{c}{ Rerata } & 19,07 & 3575,47 \\
\hline
\end{tabular}

Keterangan:

UCS : $\quad$ kuat tekan uniaksial

E : $\quad$ Modulus Young

Tegangan in situ vertikal dihitung menggunakan persamaan berikut.

$$
p_{z}=\rho g h=2,4 \text { ton } \mathrm{m}^{3} \cdot 9,8 \mathrm{~m} \mathrm{~s}^{2} \cdot 35 \mathrm{~m}=0,8 \mathrm{MPa}
$$

Pada tambang marmer bawah tanah PT Gunung Marmer Raya (PT GMR) dengan metode room and pillar, bentuk lubang bukaan adalah persegi. Untuk mengestimasi besar tegangan tangensial 
di sekitar lubang bukaan, digunakan metode perhitungan praktis dari Hoek dan Brown (1980) sebagai berikut.

$$
\begin{aligned}
\sigma_{\theta r} & =(A \times k-1) p_{z} \\
\sigma_{\theta w} & =(B-k) p_{z}
\end{aligned}
$$

Keterangan:

$\begin{array}{lll}\sigma_{\theta r} & : & \text { tegangan tangensial pada atap lubang bukaan } \\ \sigma_{\theta w} & : & \text { tegangan tangensial pada dinding lubang bukaan } \\ A & : & 1,9 \text { untuk lubang bukaan persegi } \\ B & : & 1,9 \text { untuk lubang bukaan persegi } \\ k & : & \text { rasio tegangan horizontal terhadap tegangan vertikal } \\ p_{z} & : & \text { tegangan in situ vertikal }\end{array}$

Sebelum itu, rasio tegangan horizontal terhadap tegangan vertikal $(k)$ dapat dihitung menggunakan persamaan berikut.

$$
k=0,25+7 E h(0,001+1 / z)
$$

Keterangan:

Eh : rerata modulus deformasi pada bagian atas lubang bukaan (GPa)

$z \quad: \quad$ kedalaman lubang bukaan di bawah permukaan $(\mathrm{m})$

Dari persamaan (4) hingga (7), diperoleh nilai sebagai berikut:

$$
k=0,25+7 \cdot 3,5755(0,001+1 / 35)=0,99 \approx 1
$$

Karena nilai k sama dengan 1, nilai $\sigma_{\theta r}=\sigma_{\theta w}$ yaitu $0,72 \mathrm{MPa}$. Dengan demikian,

$$
\sigma_{\theta} / \sigma_{c}=(0,72 \mathrm{MPa}) /(19,07 \mathrm{MPa})=0,04
$$

Adapun rekapitulasi parameter untuk nilai $Q$ dapat dilihat pada Tabel 3 berikut:

Tabel 3. Rekapitulasi Parameter Nilai $Q$ pada Massa Batuan Tambang Marmer PT Gunung Marmer Raya (PT GMR)

\begin{tabular}{cclr}
\hline No & Parameter & $\begin{array}{c}\text { Kondisi pada Massa Batuan Tambang Marmer } \\
\text { PT Gunung Marmer Raya (PT GMR) }\end{array}$ & Nilai/Pembobotan \\
\hline 1 & $R Q D$ & Sangat bagus & 90 \\
2 & $J n$ & Jumlah set kekar & 2,0 \\
3 & $J r$ & Mineral lempung mengisi rekahan cukup tebal & 1,0 \\
4 & $J a$ & untuk menghalangi sentuhan antara dinding & 6,0 \\
5 & $J w$ & Terkonsolidasi secara kuat, isian mineral lempung & 0,7 \\
6 & $S R F$ & Tegangan medium & 2,35 \\
\hline
\end{tabular}

Nilai Q dapat dihitung menggunakan persamaan berikut:

$$
\begin{aligned}
& Q=R Q D / J n \times J r / J a \times J w / S R F \\
& Q=90 / 2 \times 1 / 6 \times 0,7 / 2,35=2,23
\end{aligned}
$$


Nilai $Q$ tersebut kemudian dijustifikasi dengan dikalikan faktor 2,5 untuk massa batuan dengan kualitas sedang $(0,1<Q<10)$ sehingga nilai $Q$ yang digunakan pada desain adalah $5,575 \approx 6$ dengan kualitas massa batuan fair. Adapun nilai span yaitu nilai bukaan terbesar dalam lubang bukaan tanpa disangga, dalam hal ini sebesar 12 meter, sedangkan nilai Excavation Support Ratio (ESR) untuk bukaan tambang permanen bernilai 1,6.

Perencanaan pilar dilakukan dengan menentukan faktor keamanan atau Factor of Safety (FoS) pada pilar dengan persamaan sederhana:

$$
F o S=P_{s} / \sigma_{s}
$$

Keterangan:

$$
\begin{array}{ll}
F o S & =\text { faktor keamanan } \\
P S & =\text { kekuatan pilar }(\mathrm{MPa}) \\
\sigma_{S} & =\text { pembebanan pilar }(\mathrm{MPa})
\end{array}
$$

Oleh karena itu, dibutuhkan perhitungan kekuatan pilar serta perhitungan pembebanan terhadap pilar agar dapat menghitung faktor keamanan. Perhitungan kekuatan pilar menggunakan persamaan yang dikembangkan oleh Bieniawski, 1975 (dalam Bieniawski, 1984) dapat dilihat sebagai berikut.

$$
\mathrm{P}_{\mathrm{s}}=\mathrm{K} \mathrm{x}[0,64+0,34(\mathrm{w} / \mathrm{h})]
$$

Keterangan:

$$
\begin{aligned}
& \text { Ps } \quad=\text { kekuatan pilar }(\mathrm{MPa}) \\
& K=\text { nilai kuat tekan / UCS }(\mathrm{MPa}) \\
& w \quad=\text { lebar pilar (m) } \\
& h \quad=\text { tinggi pilar }(\mathrm{m})
\end{aligned}
$$

Kekuatan pilar dapat juga dihitung menggunakan persamaan yang dikembangkan oleh Obert \& Duvall (1967) sebagai berikut.

$$
\begin{array}{ll}
P S=K x[0,778+0,222(w / h)] \\
\text { Keterangan: } & \\
P S & =\text { kekuatan pilar }(\mathrm{MPa}) \\
K & =\text { nilai kuat tekan / UCS }(\mathrm{MPa}) \\
w & =\text { lebar pilar }(\mathrm{m}) \\
h & =\text { tinggi pilar }(\mathrm{m})
\end{array}
$$

Dari perhitungan yang telah dilakukan seperti di atas, diperoleh beberapa hasil yang dapat digunakan sebagai acuan untuk penentuan dimensi pilar. Dalam hal ini, dilakukan perhitungan kekuatan pilar untuk dimensi pilar $5 \mathrm{~m}$ x $6 \mathrm{~m}, 5 \mathrm{~m}$ x $9 \mathrm{~m}$, dan $5 \mathrm{~m}$ x $12 \mathrm{~m}$. Dimensi pilar $5 \mathrm{~m}$ x 5 $\mathrm{m}$ seperti rencana awal tidak direkomendasikan untuk ketinggian pilar 11 meter sebab estimasi faktor keamanan yang dihasilkannya bernilai di bawah 1 (tidak aman).

Untuk dimensi pilar $6 \mathrm{~m}$ x $5 \mathrm{~m}$, pembebanan pada pilar sebesar 14,43 MPa. Nilai ini belum melewati batas kekuatan batuan tambang marmer PT Gunung Marmer Raya (PT GMR), yaitu 19,07 MPa. Namun, ketika pilar ini digunakan untuk menyangga lubang bukaan hingga setinggi 11 meter, kondisi pilar menjadi kritis yang ditunjukkan dengan nilai estimasi faktor keamanan yang dihasilkan, yaitu 1,05. Rentang nilai faktor keamanan berdasarkan dimensi pilar tersebut 
dapat dilihat pada Tabel 4. Dapat dilihat bahwa dimensi pilar yang dapat dikatakan aman, yaitu dimensi pilar $5 \mathrm{~m}$ x $9 \mathrm{~m}$ dan $5 \mathrm{~m} \times 12 \mathrm{~m}$. Dimensi pilar $5 \mathrm{~m}$ x $6 \mathrm{~m}$ masih bisa menjadi acuan ukuran pilar, hanya saja banyak pertimbangan yang perlu dilakukan karena dimensi pilar ini tergolong ke dalam kondisi kritis jika dilihat dari hasil estimasi faktor keamanan pilar tersebut, yaitu 1,05. Dimensi pilar tersebut hanya dapat digunakan jika tidak terdapat rekahan pada pilar yang akan dibuat tersebut. Adapun rekomendasi geometri pilar yang aman hingga ketinggian pilar 11 meter dapat dilihat pada Tabel 5.

Tabel 4. Rekapitulasi Faktor Keamanan Pilar pada Kedalaman Bukaan 35 Meter di Area Tambang Marmer Bawah Tanah PT Gunung Marmer Raya (PT GMR) Menggunakan Mesin Binetti (Bieniawski, 1984)

\begin{tabular}{|c|c|c|c|c|c|c|c|c|}
\hline \multicolumn{3}{|c|}{ Dimensi Pilar } & \multirow{2}{*}{$\begin{array}{c}\text { Tinggi } \\
\text { OB } \\
\text { (m) }\end{array}$} & \multirow{2}{*}{$\begin{array}{c}\begin{array}{c}\text { Beban } \\
\text { Pilar } \\
\text { (MPa) }\end{array} \\
\begin{array}{c}\text { Szwilsky } \\
\text { (1982) }\end{array}\end{array}$} & \multicolumn{2}{|c|}{ Kekuatan Pilar (MPa) } & \multicolumn{2}{|c|}{ Faktor Keamanan } \\
\hline $\begin{array}{l}\text { Lebar } \\
\text { (m) }\end{array}$ & $\begin{array}{c}\text { Panjang } \\
\text { (m) }\end{array}$ & $\begin{array}{l}\text { Tinggi } \\
\text { (m) }\end{array}$ & & & $\begin{array}{c}\text { Obert \& } \\
\text { Duvall } \\
(1967) \\
\end{array}$ & $\begin{array}{c}\text { Bieniawski } \\
\text { (1975) }\end{array}$ & $\begin{array}{c}\text { Obert \& } \\
\text { Duvall } \\
(1967) \\
\end{array}$ & $\begin{array}{c}\text { Bieniawski } \\
\text { (1975) }\end{array}$ \\
\hline 5 & 6 & 5,5 & 35 & 14,43 & 18,69 & 18,10 & 1,30 & 1,25 \\
\hline 5 & 6 & 11 & 35 & 14,43 & 16,76 & 15,15 & 1,16 & 1,05 \\
\hline 5 & 9 & 5,5 & 35 & 11,23 & 18,69 & 18,10 & 1,66 & 1,61 \\
\hline 5 & 9 & 11 & 35 & 11,23 & 16,76 & 15,15 & 1,49 & 1,35 \\
\hline 5 & 12 & 5,5 & 35 & 9,62 & 18,69 & 18,10 & 1,94 & 1,88 \\
\hline 5 & 12 & 11 & 35 & 9,62 & 16,76 & 15,15 & 1,74 & 1,58 \\
\hline
\end{tabular}

Tabel 5. Rekomendasi Geometri Pilar Berdasarkan Perhitungan Faktor Keamanan Pilar

\begin{tabular}{lrrl}
\hline Jenis Pilar & $\begin{array}{c}\text { Lebar Pilar } \\
\text { (meter) }\end{array}$ & $\begin{array}{c}\text { Panjang Pilar } \\
\text { (meter) }\end{array}$ & \multicolumn{1}{c}{ Keterangan } \\
\hline & 5 & & $\begin{array}{l}\text { Kondisi kritis. Banyak pertimbangan } \\
\text { yang perlu diperhatikan. Tidak dapat } \\
\text { digunakan pada pilar yang terdapat } \\
\text { rekahan di dalamnya. } \\
\text { Barrier }\end{array}$ \\
Pillar & 5 & 9 & Aman \\
\hline
\end{tabular}

Nilai $Q$ dan dimensi ekuivalen (rasio span terhadap ESR) akan digunakan sebagai acuan desain penyanggaan permanen. Nilai $Q$ yang didapatkan dari hasil justifikasi yaitu 6 , nilai dimensi ekuivalen adalah 12/1,6 yaitu 7,5 sehingga rekomendasi penyanggaan yang didapatkan melalui adalah systematic bolting dan fibre reinforced sprayed concrete setebal 5-6 cm dengan jarak spasi antar-bolt 2,2 meter, atau systematic bolting tanpa lapisan concrete dengan jarak spasi antar-bolt 1,8 meter. Jika tanpa penyanggaan, ukuran bukaan terlebar (span) yang diperbolehkan adalah 5 meter berdasarkan perhitungan nilai $Q$ dan span/ESR pada Gambar 6.

Adapun pemasangan pengamanan berupa wire mesh pada atap lubang bukaan perlu di rekomendasikan untuk menghindari adanya runtuhan batuan yang lepas dan berpotensi jatuh sehingga dapat mencelakakan pekerja tambang bawah tanah. 


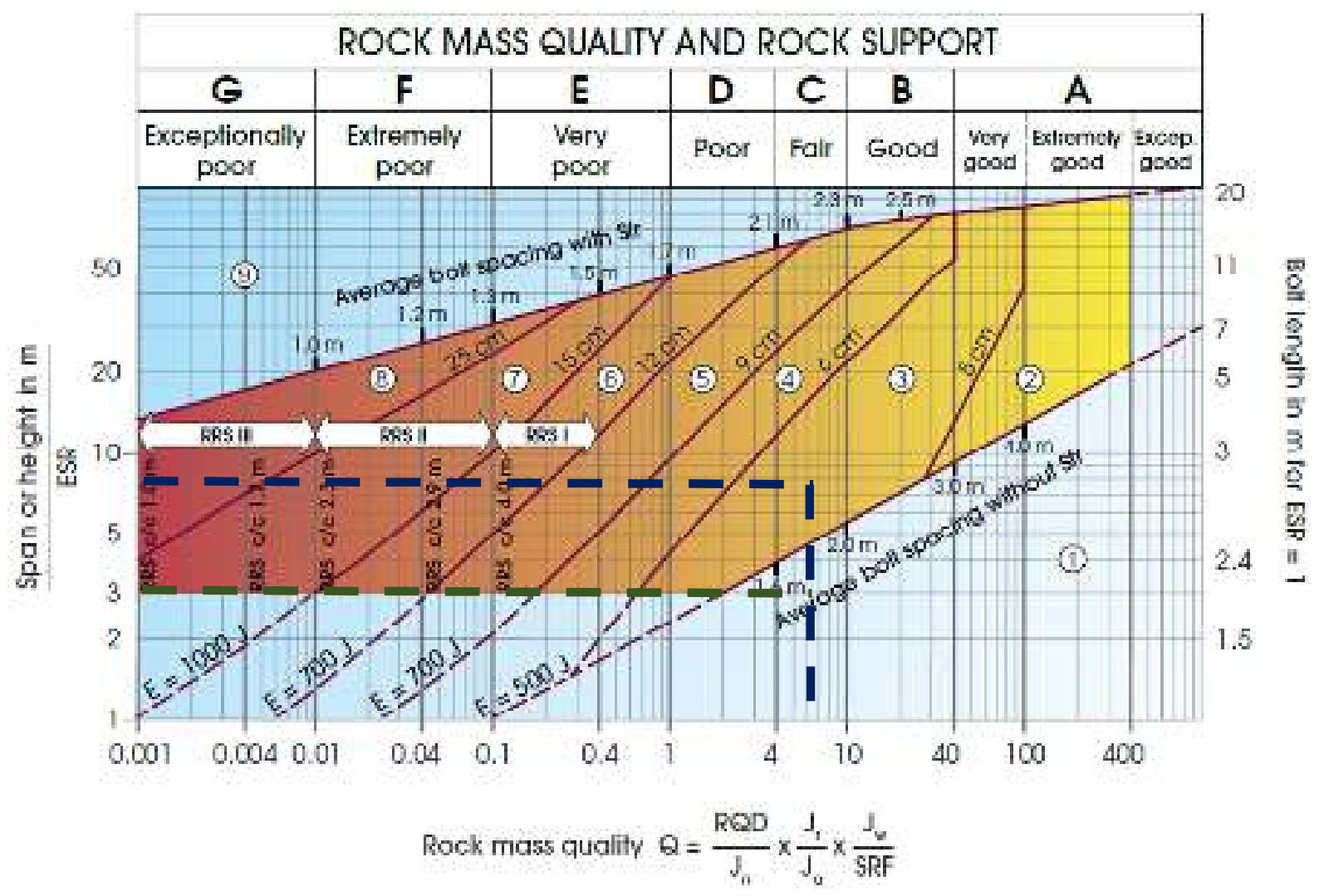

Gambar 6. Rekomendasi Penyanggaan Berdasarkan Nilai Q dan Span/ESR

Spesifikasi penguatan menggunakan rock bolt dan penyanggaan menggunakan shotcrete dapat dilihat pada Tabel 6 dan 7 berikut.

Tabel 6. Rekomendasi Spesifikasi Penguatan Menggunakan Rock Bolt

\begin{tabular}{lrrr}
\hline Length $(\mathrm{m})$ & 1.4 & 1.8 & 2.4 \\
Diameter $(\mathrm{mm})$ & 33 & 46 & 46 \\
Tensile Capacity $(\mathrm{kN})$ & 120 & 133 & 178 \\
Minimum Tensile Capacity $(\mathrm{kN})$ & 71 & 107 & 120 \\
Bolt Modulus $(\mathrm{MPa})$ & 200,000 & 200,000 & 200,000 \\
Bond Shear Stiffness $(\mathrm{MN} / \mathrm{m} / \mathrm{m})$ & 12,000 & 12,000 & 12,000 \\
Yield Strength $(\mathrm{MPa})$ & 415 & 510 & 554 \\
\hline
\end{tabular}

Tabel 7. Rekomendasi Spesifikasi Penyanggaan Menggunakan Shotcrete

\begin{tabular}{ccccc}
\hline Young's Modulus & Poisson's Ratio & Compressive Strength & Tensile Yield & Residual Yield \\
\hline $21 \mathrm{GPa}$ & 0.15 & $35 \mathrm{MPa}$ & $20 \mathrm{MPa}$ & $10 \mathrm{MPa}$ \\
\hline
\end{tabular}

\section{Kesimpulan}

Kegiatan pengabdian ini dilakukan untuk meningkatkan kestabilan pilar tambang marmer bawah tanah di PT Gunung Marmer Raya (PT GMR) sehingga aktivitas produksi dapat berlanjut, standar Kesehatan dan Keselamatan Kerja (K3) pun terpenuhi sehingga terwujud lingkungan 
kerja yang aman dan nyaman. Dari analisis yang telah dilakukan, berikut beberapa usaha yang dapat dilakukan:

1) Berdasarkan perhitungan klasifikasi massa batuan menggunakan Q-System, rekomendasi penyanggaan adalah systematic bolting dan fibre reinforced sprayed concrete setebal $5-6 \mathrm{~cm}$ dengan jarak spasi antar-bolt 2,2 meter, atau systematic bolting tanpa lapisan concrete dengan jarak spasi antar-bolt 1,8 meter;

2) Jika tanpa penyanggaan, ukuran bukaan terlebar (span) yang diperbolehkan adalah 5 meter berdasarkan perhitungan nilai Q dan span/ESR.

\section{Saran}

1) Di lokasi tambang PT Gunung Marmer Raya (PT GMR), tepatnya di lubang bukaan area produksi, terdapat bidang diskontinuitas yang merupakan struktur geologi berupa rekahan yang menerus sepanjang area produksi tersebut. Oleh karena itu, pemantauan pada rekahan ini perlu dilakukan secara rutin agar dapat diantisipasi jika rekahan menunjukkan pergerakan yang progresif. Pemantauan dapat dilakukan dengan membuat tanda pada posisi awal rekahan sehingga dapat terlihat saat posisi rekahan sudah bergeser dari posisi awal. Adapun pergeseran posisi rekahan dapat dicatat setiap kali terdapat perubahan pada posisi; dan

2) Tambang bawah tanah marmer PT Gunung Marmer Raya (PT GMR) ini menggunakan metode room and pillar. Karena terdapat kehadiran rekahan pada tambang bawah tanah ini dan terdapat kemungkinan adanya rekahan tersebut pada pilar, perlu adanya penggunaan sabuk pada sekeliling pilar yang terdapat rekahan di dalamnya tersebut.

\section{Ucapan Terima Kasih}

Ucapan terima kasih kepada Kepala Teknik Tambang (KTT) PT GMR dan jajaran staf PT GMR yang telah memfasilitasi pelaksanaan kegiatan pengabdian ini serta turut serta mendorong keaktifan para pekerja yang berkaitan dalam kegiatan ini. Ucapan terima kasih kepada seluruh tim yang tergabung dalam grup kegiatan pengabdian ini dan LBE Teknik Pertambangan Fakultas Teknik Universitas Hasanuddin.

\section{Daftar Pustaka}

Barton, N., (2015). Rock Mass Classification and Support Design Using The Q-System. Oslo: NGI.

Bieniawski, Z.T., (1984). Rock Mechanics Design in Mining and Tunneling. A.A. Balkema, Rotterdam.

Kun, M., (2014). Evaluation and Applications of Empirical Approaches and Numerical Modeling of An Underground Limestone Quarry with Room and Pillar Design. Journal of Mining Science, 50: 126.

PT Gunung Marmer Raya (2019). Profil PT Gunung Marmer Raya. Terdapat pada laman https://gmr-marble.com/?lang=id. Diakses pada tanggal 6 April 2019. 